\title{
Echocardiographic Evaluation of Left Ventricular Systolic and Diastolic Function in Hypertension
}

\author{
${ }^{1}$ Amier Ahmad, ${ }^{2}$ Navin C Nanda
}

\begin{abstract}
Hypertension is a significant health problem, i.e., associated with considerable morbidity and mortality. The hallmark of hypertensive disease is a gradual increase in left ventricular (LV) mass, resulting in concentric hypertrophy and eventual diastolic dysfunction of the left ventricle secondary to LV stiffness and impaired relaxation. Late stages may be characterized by severe LV systolic dysfunction and dilatation. Echocardiography offers clinicians a quick, reliable, and inexpensive method of assessing changes in LV function resulting from hypertension. In this review, we summarize various echocardiographic parameters, including their advantages and disadvantages, and clinicians should be familiar with in order to ascertain an assessment of cardiovascular risk in hypertensive patients.
\end{abstract}

Keywords: Echocardiography, Hypertension, Left ventricular diastolic function, Left ventricular systolic function, Three-dimensional echocardiography, Two-dimensional echocardiography.

How to cite this article: Ahmad A, Nanda NC. Echocardiographic Evaluation of Left Ventricular Systolic and Diastolic Function in Hypertension. Hypertens J 2016;2(3):113-117.

Source of support: Nil

Conflict of interest: None

\section{INTRODUCTION}

Cardiovascular diseases account for a significant amount of health problems worldwide, and hypertension is a major risk factor for cardiovascular diseases. The prevalence of systemic hypertension is estimated at $25 \%$ in the Western world, and increases dramatically with advancing age. ${ }^{1}$

The 2003 American College of Cardiology (ACC) and American Heart Association (AHA) practice guidelines recommend echocardiography as the noninvasive

\footnotetext{
${ }^{1}$ Resident Physician, ${ }^{2}$ Distinguished Professor of Medicine and Cardiovascular Disease

${ }^{1}$ Division of Internal Medicine, University of Alabama Birmingham, Alabama, USA

${ }^{2}$ Division of Cardiology, Department of Medicine, University of Alabama Birmingham, Alabama, USA

Corresponding Author: Navin C Nanda, Distinguished Professor of Medicine and Cardiovascular Disease, Division of Cardiology, Department of Medicine, University of Alabama Birmingham, Alabama, USA, Phone: +12059348256, e-mail: nanda@uab.edu
}

procedure of choice to evaluate the cardiac effects of systemic hypertension, given that it is the most common cause of left ventricular (LV) hypertrophy and congestive heart failure in adults. ${ }^{2}$ These guidelines are further supported by the 2013 European Society of Hypertension (ESH)/European Society of Cardiology (ESC) guidelines for systemic hypertension and 2014 Canadian Hypertension Education Program (CHEP) guidelines, which recommend echocardiography to not only diagnose LV hypertrophy, but also refine cardiovascular and renal risks. ${ }^{3-5}$

Hypertensive heart disease is a constellation of signs and symptoms, including LV hypertrophy, systolic and diastolic dysfunction, arrhythmias, and decompensated heart failure. ${ }^{6}$ Hypertension results in LV thickening as a compensatory response to elevated blood pressure, which through a series of poorly understood events, results in LV dilation and systolic heart failure characterized by a reduced ejection fraction (EF). ${ }^{7}$ In those hypertensive patients with preserved LV function, hypertension has been associated with gradual diastolic LV dysfunction, defined as diastolic heart failure. ${ }^{8}$ Echocardiography can quickly and cost-effectively evaluate multiple systolic and diastolic properties of the $\mathrm{LV}$, including speed and extent of contraction, end-systolic wall stress, and ventricular filling rate throughout diastole. ${ }^{9,10}$

This review aims to summarize current literature regarding echocardiographic evaluation of LV systolic and diastolic dysfunction in hypertension.

\section{SYSTOLIC DYSFUNCTION}

The paradigm of systolic dysfunction in hypertension is that hypertensive disease results in concentric hypertrophy of the LV leading to the "burned out" dilated $\mathrm{LV}$, characterized by a reduced EF. ${ }^{11}$ Left ventricular hypertrophy is defined as an increase in LV mass. Echocardiography allows for the rapid assessment of LV systolic function and M-mode and two-dimensional (2D) echocardiographic measures of LV mass have been shown to be more sensitive and specific when compared to electrocardiograms (EKG) or chest X-ray in diagnosing LV hypertrophy and concentric remodeling. ${ }^{3,12-16}$

Assessing LV mass and geometry is the most common role of echocardiography in hypertensive patients, with measurements having excellent correlation with necropsy 
study of LV mass. ${ }^{17}$ Measurements can be obtained either using the 2D directed M-mode at the level of the mitral valve tip or using $2 \mathrm{D}$ apical views. Calculating $\mathrm{LV}$ mass requires accurate measurement of both the interventricular septum and LV posterior (inferolateral) wall thickness, as well as the interventricular cavity dimension, with certain cutoff values being used to classify LV hypertrophy based on gender $\left(115 \mathrm{gm} / \mathrm{m}^{2}\right.$ men and $95 \mathrm{gm} / \mathrm{m}^{2}$ women using M-mode method, or $102 \mathrm{gm} / \mathrm{m}^{2}$ men and $88 \mathrm{gm} / \mathrm{m}^{2}$ women using 2D method). With these measurements, the American Society of Echocardiography (ASE) recommends the following equation to calculate $\mathrm{LV}$ mass:

$\mathrm{LV}$ mass $=0.8 \times 1.04 \times(\mathrm{LVIDd}+\mathrm{PWTd}+\mathrm{SWTd})^{3}+0.6$

LVIDdt (LV internal dimension at end-diastole)

PWTd (LV posterior wall thickness at end-diastole)

SWTD (interventricular septal wall thickness at end diastole)

Although this formula correlates well with necropsy studies, small variations in the measurements can result in large calculation differences. ${ }^{17}$

Three-dimensional (3D) echocardiography would provide more accurate measurements of LV mass, as it does not assume the LV to be a truncated ellipsoid as $2 \mathrm{D}$ echocardiography. The benefit of this is largely seen in patients with regional wall abnormalities or LV aneurysms, where more accurate LV volumes can be obtained by 3D vs 2D echocardiography.

Relative wall thickness (RWT) can also be calculated from measurements obtained from 2D echocardiography, and can differentiate LV hypertrophy into concentric $($ RWT $>0.42)$ or eccentric hypertrophy $($ RWT $<0.42) .{ }^{18}$ Essentially, RWT is a ratio between the end-diastolic inferolateral wall thickness and end-diastolic LV internal dimension. Concentric hypertrophy correlates with an increased number of adverse cardiovascular events and is associated with the greatest mortality rate in patients with coronary artery disease. ${ }^{19,20}$

Beyond LV mass, echocardiography allows for estimates of LV systolic function in the form of LVEF. Ejection fraction is the most common parameter of systolic function and is often used as a prognostic factor in patients with underlying heart disease, based on the severity (summarized in Table 1). ${ }^{21}$ Two methods can be used to determine EF. In the modified Simpson's method,

Table 1: Left ventricular ejection fraction (LVEF) by echocardiography stratified by gender and severity

\begin{tabular}{lll}
\hline Classification & LVEF (Men) & LVEF (Women) \\
\hline Normal LV function & $52-72 \%$ & $54-74 \%$ \\
Mild LV dysfunction & $41-51 \%$ & $41-53 \%$ \\
Moderate LV dysfunction & $30-40 \%$ & $30-40 \%$ \\
Severe LV dysfunction & $<30 \%$ & $<30 \%$ \\
\hline
\end{tabular}

the LV endocardial border is traced at end-systole/ diastole in orthogonal planes including the apex. The $\mathrm{LV}$ is then divided along the long axis into ellipsoid discs of the same height. The volume of each disk is then calculated and added to determine the LV volumes in end-systole/diastole. This method gives a single number for the EF, LV volumes, and limits variability of measurements by using computer software to calculate volumes. However, the EF is calculated from only 2 or 3 views, the LV is assumed to be ellipsoid which may not be accurate if significant wall motion abnormalities are present, and the determined EF is not reliable if LV endocardial dropouts exist. Visual estimation of EF is the most commonly practiced method. This can be an accurate method for experienced echocardiographers and has the advantage of accounting for all available views. However, there can be large variability between intra- and inter-observations with less experienced users, and this method is not useful if LV volumes are needed. Echocardiographic contrast agents have been developed which when injected intravenously make the blood in LV cavity "visible" akin to LV angiography, thereby enhancing the delineation of LV endocardial borders. These result in more accurate assessment of LVEF and $\mathrm{LV}$ volumes and less intra- and interobserver variability.

Recent advancements in 3D echocardiography offer more advantages over traditional M-mode and 2D echocardiography. Evaluation of LV mass using 3D echocardiography has high correlation $(r=0.95, p<0.001)$ with magnetic resonance imaging (MRI) ${ }^{22}$ Furthermore, 3D echocardiography measurements correlate strongly with cardiac MRI and does not assume the LV is a prolate ellipse when calculating $\mathrm{LV}$ volumes, resulting in more accurate EF measurements and lower inter-observer variability in patients with $\mathrm{LV}$ aneurysms or regional wall abnormalities. ${ }^{23-25}$ Unfortunately, the image quality is typically poorer compared to 2D modalities.

The other echocardiographic findings include LV long-axis function, assessed with atrioventricular plane displacement, that has been shown to be abnormal in patients with hypertension without obvious signs of systolic dysfunction. ${ }^{26}$ Mitral annular velocity can be used to identify subclinical systolic dysfunction and is decreased in hypertensive patients with normal EFs. ${ }^{27,28}$ Mitral annular velocity is obtained through tissue Doppler imaging, where systolic velocities $<7 \mathrm{~cm} / \mathrm{s}$ typically represent systolic dysfunction.

Speckle tracking echocardiography (STE) can be used to assess myocardium deformations by tracking natural sound markers generated by the interaction between ultrasound waves and the myocardium. It is largely angle independent with respect to the angle of insonation between the ultrasound beam and studied tissue. 
Speckle tracking echocardiography can assess for subtle myocardial dysfunction and may be clinically valuable for hypertensive patients with subclinical disease at the risk of progressing. It can be used to determine angle-independent and multidirectional myocardial strain values. Strain echocardiography is a relatively new way of measuring overall myocardial function and can be used to detect organ damage earlier than other echocardiographic measurements. Longitudinal strain has been shown to be decreased in hypertensive patients with normal LV systolic function. ${ }^{29}$ Threedimensional strain echocardiography allows analysis of the entire LV, and circumferential strain measured by 3D strain echocardiography has shown a high correlation with LVEF when compared to global longitudinal and radial strain. ${ }^{30}$

\section{DIASTOLIC DYSFUNCTION}

The relationship between LV diastolic dysfunction and hypertension is less clear and remains poorly understood. However, it is known that suboptimally treated hypertension results in LV end-diastolic pressures that are steadily increasing and to a clinical condition we recognize as diastolic heart failure, classically characterized by limited myocardial relaxation, preserved LVEF, and a significant annual mortality. ${ }^{31,32}$ There is no single echocardiographic measure that can be used to determine diastolic dysfunction. Various measurements need to be integrated to make an assessment. The ASE distinguishes various stages of diastolic dysfunction based on different echocardiographic parameters (Table 2). ${ }^{33}$

Echocardiography is a useful tool in evaluating LV diastolic function, as several echocardiographic markers can be used to estimate LV filling pressure. Enlarged left atrium (LA) size, an indicator of elevated LV filling pressure, has been documented in up to $20 \%$ of hypertensive patients, and is associated with increased morbidity and mortality. ${ }^{34-38}$ Isovolumic relaxation time (IVRT), ratio of mitral inflow E (early diastolic filling wave) and A (late diastolic/atrial filling wave) velocities, deceleration time of E velocity, and duration of A wave can all be used to assess diastolic dysfunction, although these markers are affected by several clinical entities (age, heart rate, LA function, cardiac output). ${ }^{39}$

Mitral E velocity reflects the pressure gradient between the LA and LV during early diastole. E wave deceleration correlates to LV compliance. In early diastolic dysfunction, it decreases and the A wave increases; however, with progression of diastolic dysfunction and elevation of filling pressures, the E wave velocity increases and the A wave decreases and the $\mathrm{E}$ to $\mathrm{A}$ wave ratio is elevated to $>2$. In patients with reduced EFs, the mitral E velocity correlates better with $\mathrm{LV}$ filling pressures and prognosis than LVEF. ${ }^{33}$ Prognostic information of the E/A ratio specifically in hypertensive patients has been studied as well. Schillaci et $\mathrm{al}^{40}$ followed 1839 Caucasian hypertensive patients for up to 11 years and found that E/A transmitral ratio was predictive of subsequent cardiovascular-related adverse events in untreated and uncomplicated patients with essential hypertension.

Mitral annular velocity, assessed by pulsed-wave Doppler of the medial and lateral aspects of the mitral annulus, allows for calculation of the mitral inflow E/ mitral annulus early diastolic ( $\left.\mathrm{e}^{\prime}\right)$ ratio, which has been shown to be a reliable indicator of LA pressure in certain circumstances. ${ }^{41,42}$ Mitral inflow E/ $\mathrm{e}^{\prime}$ ratio $<8$ ( $\mathrm{e}^{\prime}$ being the average of early diastolic velocities of the medial and lateral aspects of the mitral annulus) indicates normal LV filling pressure, while $>14$ is highly specific for increased LV filling pressures. ${ }^{33}$ This ratio is a poor indicator of filling pressure in patients with advanced systolic heart failure, significant valvular disease (mitral regurgitation, aortic regurgitation, and significant mitral annular calcification), and in patients with preexisting left bundle branch block. ${ }^{43-45}$ Furthermore, indeterminate values are nonspecific. ${ }^{33}$

Left atrium enlargement is a common consequence of long-term hypertension and a poor prognostic factor in hypertension. ${ }^{34}$ Left atrium size is calculated using the parasternal long-axis view at end-systole, while LA volume is calculated using apical views of traditional 2D echocardiogaraphy. ${ }^{45}$ The LA strain rate, measured by tissue Doppler imaging or 2D STE, can detect subclinical LA dysfunction in hypertensive patients. ${ }^{46}$ The LA maximum volume index represents chronic

Table 2: Echocardiographic findings according to LV diastolic dysfunction grades*

\begin{tabular}{|c|c|c|c|c|c|c|}
\hline & LV relaxation & $\angle A P$ & Mitral E/A ratio & Average E/e' ratio & Peak TR velocity $(\mathrm{m} / \mathrm{s})$ & LA volume index \\
\hline Normal & Normal & Normal & $\geq 0.8$ & $<10$ & $<2.8$ & Normal \\
\hline Grade I & Impaired & Low or normal & $\geq 0.8$ & $<10$ & $<2.8$ & Normal or ncreased \\
\hline Grade II & Impaired & Elevated & $>0.8$ to $<2$ & $10-14$ & $>2.8$ & Increased \\
\hline Grade III & Impaired & Elevated & $>2$ & $>14$ & $>2.8$ & Increased \\
\hline
\end{tabular}

${ }^{*}$ Assessment of elevated left atrial pressure is more reliable when more than 2 or 3 criteria given in the table are present in a given patient in the absence of caveats mentioned in the text. A: Mitral inflow late diastolic/atrial wave by pulsed wave Doppler; E: Mitral inflow early diastolic wave by pulsed wave; e': Average of medial and lateral mitral annulus longitudinal velocities by tissue Doppler echocardiography; LA: Left atrium; LAP: Left atrial pressure; LV: Left ventricle; TR: Tricuspid valve regurgitation 
and cumulative effects of elevated LV filling pressures. Increased LA maximum volume index is an independent predictor of death. ${ }^{33}$

\section{CONCLUSION}

Hypertension is a significant disease with considerable morbidity and mortality. Echocardiography allows for rapid, noninvasive assessment of LV function in hypertensive patients. It can evaluate morphological and hemodynamic changes acutely and over time. Because of its usefulness, it is a widely used imaging modality. Understanding the various data that can be obtained with echocardiography, as well as recent technological advances in echocardiography will aid in managing and caring for patients.

\section{REFERENCES}

1. Lloyd-Jones DM, Evans JC, Levy D. Hypertension in adults across the age spectrum: current outcomes and control in the community. JAMA 2005 Jul 27;294(4):466-472.

2. Cheitlin MD, Alpert JS, Armstrong WF, Aurigemma GP, Beller GA, Bierman FZ, Davidson TW, Davis JL, Douglas PS, Gillam LD. ACC/AHA guideline ACC/AHA/ASE 2003 guideline update for the clinical application of echocardiography: summary article. Circulation 1997 Mar 18;95(6):1686-1744.

3. Kannel WB, Gordon T, Offutt D. Left ventricular hypertrophy by electrocardiogram. Prevalence, incidence, and mortality in the Framingham study. Ann Intern Med 1969 Jul;71(1):89-105.

4. Mancia G, Fagard R, Narkiewicz K, Redon J, Zanchetti A, Böhm M, Christiaens T, Cifkova R, De BackerG, DominiczakA, et al. 2013 ESH/ESC guidelines for the management of arterial hypertension: the Task Force for the Management of Arterial Hypertension of the European Society of Hypertension (ESH) and of the European Society of Cardiology (ESC). Eur Heart J 2013 Jul;34(28):2159-2219.

5. Dasgupta K, Quinn RR, Zarnke KB, Rabi DM, Ravani P, Daskalopoulou SS, Rabkin SW, Trudeau L, Feldman RD, Cloutier L, et al. The 2014 Canadian Hypertension Education Program recommendations for blood pressure measurement, diagnosis, assessment of risk, prevention, and treatment of hypertension. Can J Cardiol 2014 May;30(5):485-501.

6. Dranzer MH. The progression of hypertensive heart disease. Circulation 2011 Jan 25;123(3):327-334.

7. FrohlichED, ApsteinC,Chobanian AV, Devereux RB,DustanHP, Dzau V, Fauad-Tarazi F, Horan MJ, Marcus M, Massie B, et al. The heart in hypertension. N Engl J Med 1992 Oct 1;327(14): 998-1008.

8. Aurigemma GP, Gaasch WH. Clinical practice. Diastolic heart failure. N Engl J Med 2004 Sep 9;351(11):1097-1105.

9. Devereux RB, Casale PN, Wallerson DC, Kligfield P, Hammond IW, Liebson PR, Campo E, Alonso DR, Laragh JH. Cost-effectiveness of echocardiography and electrocardiography for detection of left ventricular hypertrophy in patients with systemic hypertension. Hypertension 1987 Feb;9(2 Pt 2): II69-II76.

10. Devereux RB, Reichek N. Echocardiographic determination of left ventricular mass in man. Anatomic validation of the method. Circulation 1977 Apr;55(4):613-618.
11. Meerson FZ. Compensatory hyperfunction of the heart and cardiac insufficiency. Circ Res 1962 Mar;10:250-258.

12. Reichek N, Devereux RB. Left ventricular hypertrophy: relationship of anatomic, echocardiographic and electrocardiographic findings. Circulation 1981 Jun 1;63(6): 1391-1398.

13. Levy D, Garrison RJ, Savage DD, Kannel WB, Castelli WP. Prognostic implications of echocardiographically determined left ventricular mass in the Framingham Heart Study. N Engl J Med 1990 May 31;322(22):1561-1566.

14. Tsioufis C, Kokkinos P, Macmanus C, Thomopoulos C, Faselis C, Doumas M, Stefanadis C, Papademetriou V. Left ventricular hypertrophy as a determinant of renal outcome in patients with high cardiovascular risk. J Hypertens 2010 Nov;28(11):2299-2308.

15. Devereux RB, Koren MJ, de Simone G, Okin PM, Kligfield P. Methods for detection of left ventricular hypertrophy: application to hypertensive heart disease. Eur Heart J 1993 Jul;14(Suppl D):8-15.

16. Grandits GA, Liebson PR, Dianzumba S, Prineas RJ. Echocardiography in multicenter clinical trials: experience from the Treatment of Mild Hypertension Study. Control Clin Trials 1994 Oct;15(5):395-410.

17. Devereux RB, Alonso DR, Lutas EM, Gottlieb GJ, Campo E, Sachs I, Reichek N. Echocardiographic assessment of left ventricular hypertrophy: comparison to necropsy findings. Am J Cardiol 1986 Feb 15;57(6):450-458.

18. Lang RM, Bierig M, Devereux RB, Flachskampf FA, Foster E, Pellikka PA, Picard MH, Roman MJ, Seward J, Shanewise JS, et al. Recommendations for chamber quantification: a report from the American Society of Echocardiography's guidelines and standards committee and the chamber quantification writing group, developed in conjunction with the European association of echocardiography, a branch of the European society of cardiology. J Am Soc Echocardiogr 2005 Dec;18(12):1440-1463.

19. Krumholz HM, Larson M, Levy D. Prognosis of left ventricular geometric patterns in the Framingham heart study. J Am Coll Cardiol 1995 Mar 15;25(4):879-884.

20. Ghali JK, Liao Y, Cooper RS. Influence of left ventricular geometric patterns on prognosis in patients with or without coronary artery disease. J Am Coll Cardiol 1998 Jun;31(7):1635-1640.

21. Aurigemma GP, Gottdiener JS, Shemanski L, Gardin J, Kitzman D. Predictive value of systolic and diastolic function for incident congestive heart failure in the elderly: the cardiovascular health study. J Am Coll Cardiol 2001 Mar 15;37(4):1042-1048.

22. Takeuchi M, Nishikage T, Mor-Avi V, Sugeng L, Weinert L, Nakai H, Salgo IS, Gerard O, Lang RM. Measurement of left ventricular mass by real-time three-dimensional echocardiography: validation against magnetic resonance and comparison with two-dimensional and m-mode measurements. J Am Soc Echocardiogr 2008 Sep;21(9): 1001-1005.

23. Jenkins C, Bricknell K, Hanekom L, Marwick TH. Reproducibility and accuracy of echocardiographic measurements of left ventricular parameters using real-time three-dimensional echocardiography. J Am Coll Cardiol 2004 Aug 18;44(4):878-886.

24. Kuhl HP, Schreckenberg M, Rulands D, Katoh M, Schäfer W, Schummers G, Bücker A, Hanrath P, Franke A. 
High-resolution transthoracic real-time three-dimensional echocardiography: quantitation of cardiac volumes and function using semi-automatic border detection and comparison with cardiac magnetic resonance imaging. J Am Coll Cardiol 2004 Jun 2;43(11):2083-2090.

25. Gutiérrez-Chico JL, Zamorano JL, Pérez de Isla L, Orejas M, Almería C, Rodrigo JL, Ferreirós J, Serra V, Macaya C. Comparison of left ventricular volumes and ejection fractions measured by three-dimensional echocardiography versus by two-dimensional echocardiography and cardiac magnetic resonance in patients with various cardiomyopathies. Am J Cardiol 2005 Mar 15;95(6):809-813.

26. Koulouris SN, Kostopoulos KG, Triantafyllou KA, Karabinos I, Bouki TP, Karvounis HI, Omran H, Filippatos G, Kranidis AI. Impaired systolic dysfunction of left ventricular longitudinal fibers: a sign of early hypertensive cardiomyopathy. Clin Cardiol 2005 Jun;28(6):282-286.

27. Bountioukos M, Schinkel AF, Bax JJ, Lampropoulos S, Poldermans D. The impact of hypertension on systolic and diastolic left ventricular function. A tissue Doppler echocardiographic study. Am Heart J 2006 Jun;151(6):1323. e7-1323.e12.

28. Nishikage T, Nakai H, Lang RM, Takeuchi M. Subclinical left ventricular longitudinal systolic dysfunction in hypertension with no evidence of heart failure. Circ J 2008 Feb;72(2): 189-194.

29. Kang SJ, Lim HS, Choi BJ, Choi SY, Hwang GS, Yoon MH, Tahk SJ, Shin JH. Longitudinal strain and torsion assessed by two-dimensional speckle tracking correlate with the serum level of tissue inhibitor of matrix metalloproteinase-1, a marker of myocardial fibrosis, in patients with hypertension. J Am Soc Echocardiogr 2008 Aug;21(8):907-911.

30. Ishizu T, Seo Y, Kameda Y, Kawamura R, Kimura T, Shimojo N, Xu D, Murakoshi N, Aonuma K. Left ventricular strain and transmural distribution of structural remodeling in hypertensive heart disease. Hypertension 2014 Mar;63(3): 500-506.

31. MacCarthy PA, Kearney MT, Nolan J, Lee AJ, Prescott RJ, Shah AM, Brooksby WP, Fox KA. Prognosis in heart failure with preserved left ventricular systolic function: prospective cohort study. BMJ 2003 Jul 12;327(7406):78-79.

32. Vasan RS, Larson MG, Benjamin EJ, Evans JC, Reiss CK, Levy D. Congestive heart failure in subjects with normal versus reduced left ventricular ejection fraction: prevalence and mortality in a population-based cohort. J Am Coll Cardiol 1999 Jun;33(7):1948-1955.

33. Nagueh SF, Smiseth OA, Appleton CP, Byrd BF 3rd, Dokainish H, Edvardsen T, Flachskampf FA, Gillebert TC, Klein AL, Lancellotti P, et al. Recommendations for the evaluation of left ventricular diastolic function by echocardiography: an update from the American Society of Echocardiography and the European Association of Cardiovascular Imaging. J Am Soc Echocardiogr 2016 Apr;29(4):277-314.

34. Appleton CP, Galloway JM, Gonzalez MS, Gaballa M, Basnight MA. Estimation of left ventricular filling pressures using two-dimensional and Doppler echocardiography in adult patients with cardiac disease. Additional value of analyzing left atrial size, left atrial ejection fraction and the difference in duration of pulmonary venous and mitral flow velocity at atrial contraction. J Am Coll Cardiol 1993 Dec;22(7):1972-1982.

35. Russo C, Jin Z, Homma S, Rundek T, Elkind MS, Sacco RL, Di Tullio MR. Left atrial minimum volume and reservoir function as correlates of left ventricular diastolic function: impact of left ventricular systolic function. Heart 2012 May;98(10):813-820.

36. Cuspidi C, Meani S, Fusi V, Valerio C, Catini E, Sala C, Sampieri L, Magrini F, Zanchetti A. Prevalence and correlates of left atrial enlargement in essential hypertension: role of ventricular geometry and the metabolic syndrome: the evaluation of target organ damage in hypertension study. J Hypertens 2005 Apr;23(4):875-882.

37. Moller JE, Hillis GS, Oh JK, Seward JB, Reeder GS, Wright RS, Park SW, Bailey KR, Pellikka PA. Left atrial volume: a powerful predictor of survival after acute myocardial infarction. Circulation 2003 May 6;107(17):2207-2212.

38. Wu VC, Takeuchi M, Kuwaki H, Iwataki M, Nagata $Y$, Otani K, Haruki N, Yoshitani H, Tamura M, Abe H, et al. Prognostic value of la volumes assessed by transthoracic 3D echocardiography: comparison with 2D echocardiography. JACC Cardiovasc Imaging 2013 Oct;6(10):1025-1035.

39. Nagueh SF, Appleton CP, Gillebert TC, Marino PN, Oh JK, Smiseth OA, Waggoner AD, Flachskampf FA, Pellikka PA, Evangelisa A. Recommendations for the evaluation of left ventricular diastolic function by echocardiography. Eur J Echocardiogr 2009 Mar;10(2):165-193.

40. Schillaci G, Pasqualini L, Verdecchia P, Vaudo G, Marchesi S, Porcellati C, de Simone G, Mannarino E. Prognostic significance of left ventricular diastolic dysfunction in essential hypertension. J Am Coll Cardiol 2002 Jun 19;39(12): 2005-2011.

41. Sohn DW, Chai IH, Lee DJ, Kim HC, Kim HS, Oh BH, Lee MM, Park YB, Choi YS, Seo JD, et al. Assessment of mitral annulus velocity by Doppler tissue imaging in the evaluation of left ventricular diastolic function. J Am Coll Cardiol 1997 Aug;30(2):474-480.

42. NaguehSF, Mikati I, Kopelen HA, Middleton KJ, Quinones MA, Zoghbi WA. Doppler estimation of left ventricular filling pressure in sinus tachycardia. A new application of tissue Doppler imaging. Circulation 1998 Oct 20;98(16):1644-1650.

43. Park JH, Marwick TH. Use and limitations of $\mathrm{E} / \mathrm{e}^{\prime}$ to assess left ventricular filling pressure by echocardiography. J Cardiovasc Ultrasound 2011 Dec;19(4):169-173.

44. Mullens W, Borowski AG, Curtin RJ, Thomas JD, Tang WH. Tissue Doppler imaging in the estimation of intracardiac filling pressure in decompensated patients with advanced systolic heart failure. Circulation 2009 Jan 6;119(1):62-70.

45. Abhayaratna WP, Seward JB, Appleton CP, Douglas PS, Oh JK, Tajik AJ, Tsang TS. Left atrial size: physiologic determinants and clinical applications. J Am Coll Cardiol 2006 Jun 20;47(12):2357-2363.

46. Baltabaeva A, Marciniak M, Bijnens B, Parsai C, Moggridge J, Antonios TF, Macgregor GA, Sutherland GR. How to detect early left atrial remodelling and dysfunction in mildto-moderate hypertension. J Hypertens 2009 Oct;27(10): 2086-2093. 